\title{
Effect of Technical Training Using a Ball on the Dribbling Speed for Football Players Aged 10-12 Years
}

\author{
Sridadi, Tomoliyus*, Erda Ayu Septiasari, Parijan, Hari Yuliarto, Ilham \\ Faculty of Sport Sciences, Yogyakarta State University, Yogyakarta, Indonesia
}

Received May 7, 2021; Revised June 15, 2021; Accepted July 19, 2021

\section{Cite This Paper in the following Citation Styles}

(a): [1] Sridadi, Tomoliyus, Erda Ayu Septiasari, Parijan, Hari Yuliarto, Ilham , "Effect of Technical Training Using a Ball on the Dribbling Speed for Football Players Aged 10-12 Years," International Journal of Human Movement and Sports Sciences, Vol. 9, No. 4, pp. 824 - 831, 2021. DOI: 10.13189/saj.2021.090429.

(b): Sridadi, Tomoliyus, Erda Ayu Septiasari, Parijan, Hari Yuliarto, Ilham (2021). Effect of Technical Training Using a Ball on the Dribbling Speed for Football Players Aged 10-12 Years. International Journal of Human Movement and Sports Sciences, 9(4), 824 - 831. DOI: 10.13189/saj.2021.090429.

Copyright $\subseteq 2021$ by authors, all rights reserved. Authors agree that this article remains permanently open access under the terms of the Creative Commons Attribution License 4.0 International License

\begin{abstract}
Background: One of the techniques used in football activities with the ball that must be mastered by players is the dribbling technique. Coaches are required to be more careful in choosing and applying a training method so that players can accomplish the exercises quickly and correctly. Purpose: The study was to determine the extent of the effect, if any, of technical training using the ball on the dribbling speed of 10-12 years old football players. Design/methodology/approach: The design employed in this study was the One Group Pretest-Posttest Design, while the population were soccer players aged 10-12 years at the SELABORA Football School, Yogyakarta State University. Of 27 soccer players were purposely selected to be a sample of the study. Retrieval of data using tests, with an instrument in the form of a dribbling test from the Bobby Charlton model has a validity of 0.973 and reliability of 0.864 . The data were analyzed by using the t-test analysis through the prerequisite test for normality and homogeneity. Results: After addressing all data, results of hypothesis testing using t-test obtained $\mathrm{t}$-calculated of $2.324>\mathrm{t}$ table with $\alpha=0.05$. By it, data implied that there is a significant difference between the data before and after being given treatment. The increase in the mean was evident because there was an increase of 0.85 from 18.2900 to 19.1367 , with the cumulative sig equal to $0.028<0.05$. Conclusion: It can be concluded that technical training using the ball has a significant effect of $4.44 \%$ on the dribbling speed with a significant improvement between the pre-and posttest results among football players aged 10-12 years and subsequently
\end{abstract}

hypothesis posed is accepted.

Keywords Training Technique, Dribbling Speed, Football

\section{Introduction}

With its simple rules and little equipment that it requires, a football game is actually one of the most popular and likable sports in the world, primarily for young boy children [1]. Performance in soccer balls is structurally complex and dependent on many factors. The team that scoring more goals is called the winner, where reaching the goal for marking is realized through different technical behaviour [2]. It is the most important skill that children need to effectively play football. On the football field, players in possession of the ball are subjective to a tremendous amount of pressure from different opponents/adversaries. Thus, to be an effective player, she/he must be able to confront different strength by dribbling and control the ball with their both feet. According to [3], the ability to offset the ball is one of the most important skills in football counted in players. The success of the team merely depends on its players' ability to dribble [4] and maintain ball possession. Dribbling performance appears to be the single most important skill compared to passing, first touch, and defence [5]. To play soccer compiles a sizeable number of important dribbling 
skills necessary, for example, being able to change speeds with the ball, such as accelerating, stopping, swerve direction, and so forth. Dribbling speed is considered as a critical asset to the game outcome [6]. Players need to be able to use the inside, outside, sole, and instep of both feet to change or stop the ball directions.

Ball control is an exceptionally essential skill for football/soccer players since able to deliberately performing successful dribbling significantly while changing direction is required to achieve successful performances [7], [8], [9]. However, the importance of these skills needed in soccer can vary between players and different field playing positions. Soccer players can be roughly divided into three prominent positions based on players' skills (guard, forward, centre), which each has slightly different roles to execute. By it, some players often spend many hours in training just in the wake of improving those skills which are especially important in their chosen sport (e.g., ball control in soccer ball) [7], [10]. According to [11], at least 10000 hours or ten years of deliberate practise are needed to meet expertise level.

Training practice, especially in football, is the primary tool in the daily training process to improve the quality of the functioning of the human organ systems, making it easier for athletes to perfect their movements. This late statement is in line with [12] explaining that training is a systematic process of practising or repeatedly working with an increase in the number of exercises or workloads. In tandem, [13] suggests that the one-to-face training arrangement contains some systematic steps where among others, (1) Opening / introducing training, (2) warming up, (3) core training, (4) additional training (supplement), and eventually (5) Cooling down. Overall, technical training is simply understood as the process of improving one's ability to master sports skills which can be provided in the form of theoretical and practical explanations. Yet, it is carried out regularly, measured, and continuously in a very specific way so that the material can be adequately mastered.

As introduced in the proceeding section, dribbling a soccer ball is easy and difficult for some individuals. It can be of the most effortless and natural skills to perform. For that reason, young children like to enjoy naturally playing football either in the cities or remote areas, so that they can run freely while kicking the ball. However, in general, the challenge comes from keeping it close when controlling or misleading the ball to suddenly change speeds and directions in an effort to beat the adversary. Basically, four main types of dribbling techniques are acknowledged so far, that is, speed dribbling, shielding, faking, and cutting [4]. In soccer-playing, these aforementioned techniques are all necessary skills that players must acquire and purposely combined to beat an opponent. [14] defined dribbling speed as a critical performance to the outcome of the game. The same author also considers it as one of the first dribbling techniques children learn and acquire, which is most similar to a natural step while tapping the ball at a fast speed with the instep or shoelaces. However, the main problem to master with dribbling techniques often seeming with the unskilled player is the manner to control the ball with a soft touch, and thereby the player does not push it too far ahead for the defender to steal. [4], [7] stated that keeping the ball close, using both feet, having soft touches, and looking at a 45-degree angle are the crucial cues players should apply or present while performing the dribbling activity in a soccer game. Mainly many young children fascinated by football playing want to poke the ball with the toes, and subsequently causing the ball to roll too far ahead of them. For that reason, [15] stated that these solid and soft skills, ball control, and feeling could only be learned through repeatedly touching the ball as training techniques indeed. The main purpose of applying speed dribbling is to advance the ball into your opponent's space as quickly as possible, especially when there is free space ahead of you.

Shielding the ball is another characteristic of the best dribblers, that is, the ability to hold the ball under pressure or shield dribble. It can be done while standing still or while moving with the ball. [16] shielding is most often applied when players run out of room to dribble and are tightly marked or when simply cannot outrun a chasing adversary. Skilled dribblers in a football game can shield the ball to maintain possession, which then increases their team's opportunity creation and chances of winning. Ball handlers who are proficient at shielding usually are very confident with controlling and dribbling the ball.

Apart from the shielding, soccer players must also be able to effectively dribble the ball, which leads the player to complete on a competitive level. A fake performance is another type of dribbling technique simply accounted for when the ball handler deceives the defender. The possibility to use his/her body to fake the defender by the ball handler with a shoulder lean or step fake to the side to give the impression is called deception. According to [17], the attacker uses their body friend and tries to disguise his/her intentions so that the defenders suddenly make a wrong move and get off the balance. As a result, it is to get the opponent defender to learn off-balanced to one side. In the manual Play like a soccer legend, a number of fakes are listed and taught to soccer players, such as the Sir Stanley Mathews fake, the Roberto Rivelino fake, Karl-Heinz Rummenigge fake, and Geoff Hurst fake.

In broad terms, the sir Stanley Mathews fake is used when players from the opponent group face the defender while standing nearly still, whereas, in the Roberto Revelino fake, the player fakes kick the ball but instead step around it and plant the foot on the far side of the ball. In the Karl-Heinz Rummenigge fake, the player swings his/her foot around the front of the ball and takes a step to the side. Thus, this technique gives the defender the impression you are moving or passing the ball in this 
direction.

In the cutting dribbling strategy, cutting the ball allows the ball handler to move the ball in their desired direction. According to [18], [3], when an opponent closes in on them, the players also need to learn how to escape or do spinning to move in a new direction. So, to be a successful player in cutting the ball, the inside, outside, and sole of the foot are used. As presented in the previous section, a soccer ball is still the most popular sport in the world [19], [20], and a high-intensity team sport that requires a good amount of physical and physical abilities. Dribbling speed, agility, and strength are among the high levels of aerobic and anaerobic conditioning that soccer players must develop and maintain in the wake of easing in the field performance. Many young children, adolescents, and even adults play soccer for pleasure or as a profession [21]. For children, some are well skilled in ball control since the low age whereas others not. Due to this disparity in skills, soccer coaches must work in an integrated manner to ensure a structured and effective program simply known as technical training, and agility in players as the main components of soccer training [20]. Based on the results of observations of the school of a soccer ball at Yogyakarta State University, it has found that there are still many students who have not been able to play football properly, especially in the speed of dribbling [1], [7]. UNY soccer school students have several groups fostering separately based on different age groups, where one of them is a group of 10-12 years. The results of observations of different matches on the SSB SELABORA at UNY U-12 team lacked agility, balance in dribbling speed; thereby, the ball was often and easily taken by the opponent. Therefore, it needs for empowering dribbling speed, agility in ball control, and balance. Worthy also mentioning that dribbling properly, especially in football games, requires good speed and support from elements of good physical conditions and agility in ball control [22]. With a lot of repetition methods as technical training using a ball on the dribbling speed of football players aged 10-12 years, the ability to dribble quickly and properly and agile can be achieved and displayed in the match. Also, to determine the extent to which is the effect of technical training by using a ball on the dribbling speed among young players, this study was driven by a research hypothesis as "there is an effect of technical training using the ball on the dribbling speed of football players aged 10-12 years at SSB SELABORA Yogyakarta State University."

\section{Material and Method}

This research is quasi-experimental and wants to determine the extent of the cause-and-effect relationship caused by a treatment applied to young football players. This study employed the One Group Pretest Posttest Design, where the researcher wanted to compare the pretest and posttest of the dribbling speed of football players aged 10-12 years, Yogyakarta State University. A number of 27 young players as the research sample was purposively selected. Instruments used in this study was an instrument made by Bobby Charlton, which was developed to measure the speed of a dribble [23], [24], [25], which has a validity of 0.973 and reliability of 0.864 . The treatment given to 27 students of SSB SELABORA was 16 times with the provision of technical training material using balls including ball felling, dribbling, controlling, keeping, and passing, which were given alternately with the frequency of training three times a week.

Star

Finish

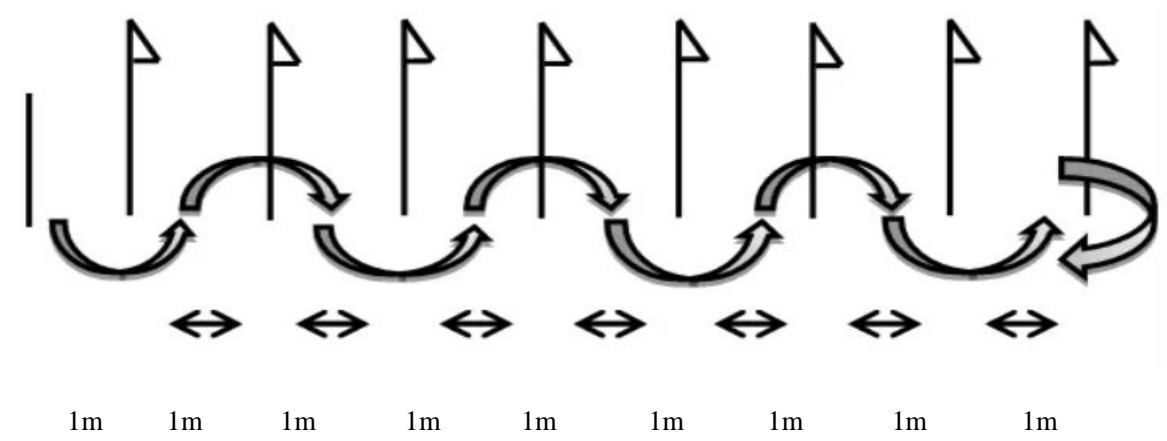

Picture 1. Instrument of dribbling Bobby Charlton 


\section{Explanation}

Equipment: 8 pieces of cone or iron stake, one ball of size 4, and a stopwatch. Implementation: the ball is placed 1 meter from the first stake (starting line), the player prepares for the starting position, after hearing the tester's/trainer cue, the player starts dribbling over the eight stakes and returns to the finish line, the ball is stopped right at the finish line, use the feet it is best to dribble, each child does two times and the best time is taken.

\section{Results and Formula}

Worthy of imparting that, this study used two types of data. The first data was determined by the value of the pretest results, whereas the posttest results determined the second treatment data. The data for the two treatments can be seen in the following table;

Table 1. Data of Pre- and Pos-Test Treatment

\begin{tabular}{|c|c|c|}
\hline Subject & Pretest & Post-Test \\
\hline 1 & 19.81 & 18.56 \\
\hline 2 & 18.63 & 17.81 \\
\hline 3 & 17.87 & 18.34 \\
\hline 4 & 18.71 & 18.30 \\
\hline 5 & 15.08 & 14.50 \\
\hline 6 & 16.70 & 18.84 \\
\hline 7 & 25.42 & 23.13 \\
\hline 8 & 19.80 & 20.05 \\
\hline 9 & 22.96 & 16.18 \\
\hline 10 & 22.27 & 19.64 \\
\hline 11 & 17.21 & 17.36 \\
\hline 12 & 18.23 & 17.10 \\
\hline 13 & 16.84 & 14.30 \\
\hline 14 & 16.10 & 18.75 \\
\hline 15 & 16.22 & 17.77 \\
\hline 16 & 17.00 & 17.90 \\
\hline 17 & 19.13 & 18.70 \\
\hline 18 & 16.99 & 17.62 \\
\hline 19 & 18.54 & 17.40 \\
\hline 20 & 19.40 & 19.24 \\
\hline 21 & 17.42 & 17.36 \\
\hline 22 & 16.45 & 15.89 \\
\hline 23 & 18.35 & 17.19 \\
\hline 24 & 23.15 & 21.03 \\
\hline 25 & 23.40 & 20.09 \\
\hline 26 & 21.20 & 19.73 \\
\hline 27 & 23.81 & 21.05 \\
\hline
\end{tabular}

A paired t-test (paired t-test) is one method of testing the hypothesis where the data used are not independent (pairs). Characteristics that are most often found in paired cases is one individual (object of research) gets two different treatments. Even though using the same individual, researchers still obtained two types of sample data, namely data from the first treatment and data from the second treatment.

The hypothesis of this case can be written as follows:

$$
\begin{aligned}
& \mathrm{H} 0=\mu 1-\mu 2=0 \\
& \mathrm{H} 1=\mu 1-\mu 2 \neq 0
\end{aligned}
$$

$\mathrm{Ha}$; means that the actual difference from both means is not equal to zero.

\section{The Short Formula of Paired t-Test}

$$
\text { t-calculated }=D^{-} / S D / \sqrt{ } n
$$

With:

$$
\begin{aligned}
& S D=\sqrt{ } \text { var } \\
& (s 2)=1 / n-1 \sum(x i-\bar{x}) 2 \\
& i=1
\end{aligned}
$$

\section{Interpretation/Profile}

a) To interpret the t-test results, the following values must first be determined:

- $\quad$ Significant value alpha $(\alpha)$

- $\quad$ Df (degree of freedom) $=\mathrm{N}-\mathrm{k}$, only for paired sample t-test, $d f=N-1$

b) comparing values of t-calculated with t-table $=\alpha ; n-1$;

c) If,

- $t$-calculated $>t$-table, means significantly different, then, (Ho, rejected);

- $\quad t$-calculated $<t$-table, means not significantly different, then, (Ho, get accepted).

\section{Results and SPSS Output}

The summary of the research prerequisite test calculation results, namely the normality test and the homogeneity test, can be seen in the tables below.

Table 2. Results Normality Testing Output

\begin{tabular}{|c|c|c|c|c|c|c|}
\hline No & Variable & $\chi^{2}$ calculated & df & $\chi^{\mathbf{2}} \mathbf{( 0 , 0 5 ) ( d f )}$ & Sig & Conclusion \\
\hline 1 & Pretest Experiment & 0,000 & 26 & 38.88 & 1,000 & Normal \\
\hline 2 & Post Test Experiment & 0,926 & 25 & 37.65 & 1,000 & Normal \\
\hline
\end{tabular}


Table 3. Summary of Homogeneity Testing Results

\begin{tabular}{|c|c|c|c|c|}
\hline No & Cohort & F-calculated & Sig & Description \\
\hline 1 & Pretest Experiment & 3.941 & 0.052 & Humogen \\
\hline 2 & Posttest Experiment & & & \\
\hline
\end{tabular}

Table 4. The results of Paired Sample Statistics

\begin{tabular}{|c|c|c|c|c|c|}
\hline \multicolumn{6}{|c|}{ Paired Samples Statistics } \\
\hline & & Mean & $\mathbf{N}$ & Std. Deviation & Std. Error Mean \\
\hline \multirow{2}{*}{ Pair 1} & Pretest & 19.1367 & 27 & 2.75644 & .53048 \\
\hline & Post-test & 18.2900 & 27 & 1.93342 & .37209 \\
\hline
\end{tabular}

Table 5. Output Paired sample Correlation

\begin{tabular}{|c|c|c|c|c|}
\hline \multicolumn{7}{|c|}{ Paired Samples Correlations } \\
\hline \multicolumn{2}{|c|}{} & N & Correlation & Sig. \\
\hline Pair 1 & Pre-test \& Post-test & 27 & .727 & .000 \\
\hline
\end{tabular}

Table 6. Profile Output Paired Samples Test

\begin{tabular}{|c|c|c|c|c|c|c|c|c|c|}
\hline \multicolumn{10}{|c|}{ Paired Samples Test } \\
\hline & & \multicolumn{5}{|c|}{ Paired Differences } & \multirow{3}{*}{$\mathrm{t}$} & \multirow{3}{*}{$\mathrm{df}$} & Sig. (2-tailed) \\
\hline & & \multirow{2}{*}{ Mean } & \multirow{2}{*}{$\begin{array}{c}\text { Std. } \\
\text { Deviation }\end{array}$} & \multirow{2}{*}{$\begin{array}{l}\text { Std. Error } \\
\text { Mean }\end{array}$} & \multicolumn{2}{|c|}{$\begin{array}{c}\text { 95\% Confidence Interval of } \\
\text { the Difference }\end{array}$} & & & \\
\hline & & & & & Lower & Upper & & & \\
\hline Pair 1 & Pre-test Post-test & .84667 & 1.89292 & .36429 & .09785 & 1.59548 & 2.324 & 26 & .028 \\
\hline
\end{tabular}

Data analysis was performed by t-test on the pretest and posttest data on the results of the dribbling speed measurement. This test will test the research hypothesis. To accept or reject the hypothesis by comparing the $t$-value with the t-table value. The alternative hypothesis is accepted if the t-counted/calculated is greater than the t-table with a significance of 0.05 ( $p$-value). To find out the difference in ball dribbling speed between before being given a technical training exercise using a ball and dribbling speed after being given a technical training exercise using a ball, a two-sample related t-test or paired sample t-test was used. The results of the t-test are shown in the following table.

It is worth acknowledging that, paired sample t-test is a test used to compare the difference between two means of two paired samples with the assumption that the data are normally distributed. Paired samples come from the same subject, and each variable is taken when the situation and circumstances are different. Thus, the results of the analysis can be viewed in the table 4 .

Table 4 shows the results of descriptive statistic from pretest and posttest data used. As seen here, there are two different means found; for pretest, the mean value is equal to 19.1367 , while for posttest results, the same mean value is 18.2900 , with $N$ as the sample size of 27 individuals on both sides. Shortly, this table describes the characteristic of the subjects used in term of descriptive statistic where mean, $\mathrm{N}$, and standard deviation data are presented.

Nevertheless, for Paired sample correlations, results present whether pretest and posttest data have a strong correlation; in other words, they have significant correlations in between. With the assumption that if sig < 0.05 , then means there is a significant correlation. In this study, sig calculated is equal to .000 or inferior to .05 , that said between pretest and posttest data shows a strong relationship.

The table depicted above shows the results of the t-test of 2.324. With a significant value of alpha $=0.05$, then $\mathrm{t}$-table $=2.120$. So, it can be concluded that t-calculated $>$ t-table. In other words, the treatment carried out in the study has a sufficient effect significant to the expected results.

As depicted in the table, sig. (2-tailed) equal to $0.028<0.05$, then there is a [positive effect of the treatment applied. This significant effect can also be identified through the pre-and post-test results.

The t-test results were obtained by the t-value of 2.324 with a significance level of 0.028. Therefore, t-calculated $>$ t-table with a significance value of 0.05 and $\mathrm{df}=\mathrm{n}-2$, so that the t-table is 0.708 , thus means that Ha hypothesis is accepted, and Ho is rejected. Then with this data dealt with, it can be concluded that there is a significant difference in the results of dribbling speed between young football players before and after the 
experiment was carried out.

Based on the table above, it can be seen that the average value for pretest data is 19.1367 , whereas the average value for posttest data is 18.2900 . These results indicate the dribbling speed after being treated with technical training using the ball increased by $4.44 \%$. In this case, it can be said that the effect of technical training using the ball on the dribbling speed is effective and significant.

\section{Discussion}

To begin with, this study aims to determine the effect of technical training using the ball on the dribbling speed of football players aged 10-12 years. Data analysis and research results show that there is a significant difference in the speed of dribbling before and after the technical exercise using the ball was applied.

At the time of the pretest, the average dribbling speed was 19.1367, while at the time of the posttest, the average magnitude of the dribbling was 18.2900. It turned out that after being given technical training using a ball, the mean magnitude of the experimental group changed to an increase of 0.85 or $4.44 \%$. The t-test analysis shows that there is a significant difference, so this shows that it turns out that technical training using the ball has a significant effect on increasing the dribbling speed of football players aged 10-12 years at the SELABORA Football School, Yogyakarta State University. Technical training effect in dribbling speed was also found in the study of [1] while examining the effect of futsal balls on the passing and dribbling skills of 11-12-year-old soccer players. As a result, the soccer players in the game who train with heavier and less bouncy futsal balls make contact with the ball more often. Moreover, data showed also that they become more focused, which results in an enhancement in their game skills and also has a positive effect on traditional soccer games [26], [27].

Technical training using the ball is a form of exercise that leads to dribbling skills. It is given with several forms of training as well as in several forms of games and tests. This aims to encourage children to make fast, aggressive, and active movements. The elements contained in technical training using the ball cannot be separated from the speed factor. In a soccer game, using a ball technique is a necessary condition so that the instinct for the ball is not lost. The basic concept for increasing the speed of playing football is with a correct and targeted training program, for example, by increasing training load, increasing training, and varying forms of training. With technical training using the ball, players will get used to playing the ball using their feet at varying speeds [28], [29] so that players will be able to do dribbling at high speed [30].

The dribbling speed of football players aged 10-12 years is still classified as unstable. That said that it could change according to the repetitive training they do, both from the type of exercise, training intensity, and the frequency of training [31], particularly for football players aged 10-12 years at the SELABORA Football School, Yogyakarta State University. This research was carried out by giving 27 players a technical training exercise using the ball for 16 training sessions; it turns out that the training method has a significant effect on dribbling speed. It is known that after the experiment, there was an increase in dribbling speed by 0.85 or $4.44 \%$. The results achieved are under the objectives of technical training using the ball, namely increasing dribbling speed [32]. Because players are accustomed to playing the ball at varying speeds, their instincts for the ball are increasingly honed, where the key to success in dribbling the ball always emphasizes the position or distance of the ball with the feet not too far [33], so that it is expected to be able to do dribbling at high speed.

\section{Conclusions}

Based on the results of data analysis, hypothesis testing, and discussion, the conclusions in this study are as follows: "There is an effect of technical training using the ball on the dribbling speed of football players aged 10-12 years at SSB SELABORA Yogyakarta State University, which stands at $4.44 \%$." Thus, the alternative hypothesis is accepted.

\section{Acknowledgements}

The authors express gratitude to the experts of the Yogyakarta state university lecturer in sport science indeed, instructor, and players aged 10-12 Years at the SELABORA football school, Yogyakarta State University.

\section{REFERENCES}

[1] A. Caglayan, K. Erdem, V. Colak, and N. Ozbar, "The Effects of Trainings with Futsal Ball on Dribbling and Passing Skills on Youth Soccer Players," Int. J. Appl. Exerc. Physiol., vol. 7, no. 3, pp. 2322-3537, 2018, doi: 10.30472/ijaep.v7i3.282.

[2] H. Nunome, Y. Ikegami, R. Kozakai, T. Apriantono, and S. Sano, "Segmental dynamics of soccer instep kicking with the preferred and non-preferred leg," J. Sports Sci., vol. 24, no. 5, pp. 529-541, 2006, doi: $10.1080 / 02640410500298024$.

[3] B. Keskin, "The effects on soccer passing skills when warming up with two different sized soccer balls," Educ. Res. Rev., vol. 10, no. 22, pp. 2860-2868, 2015, doi: 10.5897/err2015.2444. 
[4] K. S. Miller, "The effects on soccer dribbling skills when training with two different sized soccer balls,” J. Chem. Inf. Model., vol. 53, no. 9, pp. 1689-1699, 2017, [Online]. Available: file:///C:/Users/User/Downloads/fvm939e.pdf.

[5] C. Thomas, G. Fellingham, and P. Vehrs, "Development of a notational analysis system for selected soccer skills of a women's college team,” Meas. Phys. Educ. Exerc. Sci., vol. 13, no. 2, pp. 108-121, 2009, doi: 10.1080/10913670902812770.

[6] B. C. H. Huijgen, M. T. Elferink-Gemser, W. J. Post, and C. Visscher, "Soccer skill development in professionals," Int. J. Sports Med., vol. 30, no. 8, pp. 585-591, 2009, doi: 10.1055/s-0029-1202354.

[7] S. C. M. te Wierike, B. C. H. Huijgen, L. Jonker, M. T. Elferink-Gemser, and C. Visscher, "The importance and development of ball control and (self-reported) self-regulatory skills in basketball players for different positions,” J. Sports Sci., vol. 36, no. 6, pp. 710-716, 2018, doi: 10.1080/02640414.2017.1334954.

[8] C. C., T. A., L. C., P. C., F. E., and F. F., "Inter-limb coordination, strength, jump, and sprint performances following a youth men's basketball game,” J. Strength Cond. Res., vol. 25, no. 1, pp. 135-142, 2011, [Online]. Available: http://ovidsp.ovid.com/ovidweb.cgi?T=JS\&PA $\mathrm{GE}=$ reference $\& \mathrm{D}=$ emed $10 \& \mathrm{NEWS}=\mathrm{N} \& \mathrm{AN}=20885333$.

[9] J. Torres-Unda et al., "Anthropometric, physiological and maturational characteristics in selected elite and non-elite male adolescent basketball players,” J. Sports Sci., vol. 31, no. 2, pp. 196-203, 2013, doi: 10.1080/02640414.2012.725133.

[10] P. Ward, N. J. Hodges, J. L. Starkes, and M. A. Williams, "The road to excellence: Deliberate practice and the development of expertise,” High Abil. Stud., vol. 18, no. 2, pp. 119-153, 2007, doi: 10.1080/13598130701709715.

[11] B. N. Macnamara and M. Maitra, “The role of deliberate practice in expert performance: Revisiting Ericsson, Krampe \& Tesch-Römer (1993),” R. Soc. Open Sci., vol. 6, no. 8, 2019, doi: 10.1098/rsos.190327.

[12] P. Studi, P. Ekonomi, J. Pendidikan, and I. Pengetahuan, Fakultas keguruan dan ilmu pendidikan universitas jember 2014. 2014

[13] B. Van Hooren and J. M. Peake, "Do We Need a Cool-Down After Exercise? A Narrative Review of the Psychophysiological Effects and the Effects on Performance, Injuries and the Long-Term Adaptive Response,” Sport. Med., vol. 48, no. 7, pp. 1575-1595, 2018, doi: 10.1007/s40279-018-0916-2.

[14] M. Zago, A. G. Piovan, I. Annoni, D. Ciprandi, F. M. Iaia, and C. Sforza, "Dribbling determinants in sub-elite youth soccer players,” J. Sports Sci., vol. 34, no. 5, pp. 411-419, 2016, doi: 10.1080/02640414.2015.1057210.

[15] S. Wondirad and D. Atomsa, "The effect of ten weeks mixed football training program on dribbling, passing and shooting performance of Jimma University and Jimma Tesfa male football project," Int. J. Phys. Educ. Sport. Heal., vol. 6, no. 5, pp. 1-4, 2019.
[16] T. Manager and A. Link, "How to Shield the Ball in Soccer and 4 Essential Drills.”

[17] A. Pfleegor, “Adam Pfleegor (C) December, 2010,” 2010.

[18] I. N. S. Systems, S. E. E. Engineering, and A. Q. U. P. Perspective, "F Actors R Elated To the I Implementation of," vol. 11, no. August, pp. 344-349, 2008.

[19] D. C. F. Silva, R. Santos, J. P. Vilas-Boas, R. Macedo, A. M. Montes, and A. S. P. Sousa, "Influence of Cleats-Surface Interaction on the Performance and Risk of Injury in Soccer: A Systematic Review,” Appl. Bionics Biomech., vol. 2017, no. June, 2017, doi: 10.1155/2017/1305479.

[20] D. Abidin, M. Muhamad, A. Haqiyah, and A. R. Gusriadi, "Agility and Balance on the Speed of Dribbling in Soccer," no. July 2020, doi: 10.2991/assert.k.200219.059.

[21] M. EMIRZEOĞLU and Ö. ÜLGER, "Comparison of the Dynamic Balance and Speed Performance of Soccer Players Playing in Different Positions,” Turkiye Klin. J. Sport. Sci., vol. 12, no. 1, pp. 16-22, 2020, doi: 10.5336/sportsci.2019-71384.

[22] T. Reilly, A. M. Williams, A. Nevill, and A. Franks, "A multidisciplinary approach to talent identification in soccer," J. Sports Sci., vol. 18, no. 9, pp. 695-702, 2000, doi: $10.1080 / 02640410050120078$.

[23] P. V Kadagadakai and B. Pradhan, "Study of physical fitness and technical skills on college soccer players playing positions,” pp. 22-26, 2018.

[24] A. Ridwan and Juhanis, "The Effect of Running Practice Method on Football Shooting Skills of Sport Science Students BT - 3rd International Conference on Education, Science, and Technology (ICEST 2019),” vol. 481, no. Icest 2019, pp. 291-295, 2020, [Online]. Available: https://doi.org/10.2991/assehr.k.201027.061.

[25] A. V. Irfansyah et al., "The Effect of Dribble Clap Training on Dribbling Capabilities of Team U-15 SSB Chevron Pekan Baru. Pengaruh Latihan Tepukan Dribble Terhadap Kemampuan Dribbling Tim U-15 SSB,” pp. 1-12.

[26] C. H. Almeida, A. P. Ferreira, and A. Volossovitch, "Offensive sequences in youth soccer: Effects of experience and small-sided games,” J. Hum. Kinet., vol. 36, no. 1, pp. 97-106, 2013, doi: 10.2478/hukin-2013-0010.

[27] G. Tabacchi et al., "Field-based tests for the assessment of physical fitness in children and adolescents practicing sport: A systematic review within the ESA program,” Sustain., vol. 11, no. 24, 2019, doi: 10.3390/su11247187.

[28] D. Armando and H. A. Rahman, "The Effect of Training Methods and Eye-Foot Coordination on Dribbling Abilities in Students Aged 12 - 13 Years," Acta Fac. Educ. Phys. Univ. Comenianae, vol. 60, no. 1, pp. 117-133, 2020, doi: 10.2478/afepuc-2020-0010.

[29] M. Hasnun, A. Hassan, and Z. Taha, "Development of a Soccer Ball Launching Device Development of a Soccer Ball Launching Device Soccer is the most popular sport in the world with an active involvement of more than," no. January, 2018, doi: 10.1007/978-981-10-8788-2. 
[30] J. Arwandi and M. Firdaus, "Effect of Agility Training Towards Soccer Dribbling Skills,” vol. 35, no. Icssht 2019, pp. 7-10, 2021, doi: 10.2991/ahsr.k.210130.002.

[31] Z. Kong, F. Qi, and Q. Shi, “The influence of basketball dribbling on repeated high-intensity intermittent runs,” $J$.
Exerc. Sci. Fit., vol. 13, no. 2, pp. 117-122, 2015, doi: 10.1016/j.jesf.2015.10.001.

[32] Ertheo, “The Football MVP Handbook,” Educ. Sport., pp. 4-24, 2001.

[33] “2002 Sample-of-Ele-BB-Practice-75-Mins.pdf.” 